\title{
Rectal Perforation, CTCAE 5.0
}

National Cancer Institute

\section{Source}

National Cancer Institute. Rectal Perforation, CT CAE 5.0. NCI Thesaurus. Code C146634.

A disorder characterized by a rupture in the rectal wall. 